\title{
WAVES GENERATED BY TWO OR MORE SHIPS IN A CHANNEL
}

\author{
Maria Francisca do Nascimento ${ }^{1}$, Claudio F. Neves ${ }^{2}$ and Geraldo de Freitas Maciel $^{3}$
}

The numerical model FUNWAVE+Ship simulates the generation and propagation of ship waves to shore, including phenomena such as refraction, diffraction, currents and breaking of waves. The interaction of two wave trains, generated by ships moving either in the same direction at different speeds or in opposite directions, is studied. Focus is given to the wave orbital velocities and to the free surface pattern.

Keywords: ship waves; Boussinesq waves; wave refraction; wave-wave interaction; orbital velocities

\section{INTRODUCTION}

Ship waves in narrow channels are an issue of special concern to stability of the margins of waterways. Physical models and field observations have been useful resources to study this type of waves, whereas numerical models have focused mostly on wave generation and ship resistance. Nowadays, numerical models have been largely used as a reference guide to assess the risks of embankment erosion, offering many advantages as compared to small scale physical models such as low operational cost, short time response, and quick evaluation of environmental impacts. Yet, several features related to ship waves and their interaction with shore structures, bottom morphology, and anchored boats need field observations and laboratory experiments in order to be better assessed. In the (near) future, though, combined physical-numerical models and in situ observations (e.g. Chwang and Chen, 2003) will form a comprehensive toolbox for research about the subject, in order to improve waterway design and operational conditions.

Nascimento (2007) presented a numerical model for ship wave propagation (FUNWAVE+Ship) based on Boussinesq equations (Wei and Kirby, 1995), where an additional moving pressure at the free surface was introduced into the momentum equations as a source function, in order to simulate the generation of ship waves. This model reproduces most phenomena related to wave propagation, such as bottom and current refraction, diffraction, frequency dispersion, energy transfer among components, bottom dissipation and breaking. The results of this model were compared to laboratory measurements and numerical results presented in the literature, showing very good agreement (Nascimento et al., 2008).

It turns out that navigation in waterways very seldom occurs with one single ship, and tidal or river currents may also be present. Interaction among waves generated by two or more ships is an important subject (Zhu et al. 2008). Figure 1 shows an example of the resulting free surface, after the passage of many boats during a fish boat parade at Cuiabá River, in the Western part of Brazil. Clearly the superposition of the waves generated by each individual boat creates a complex pattern. In this case, a numerical model becomes a useful resource as a guide to subsequent monitoring programs in the field.
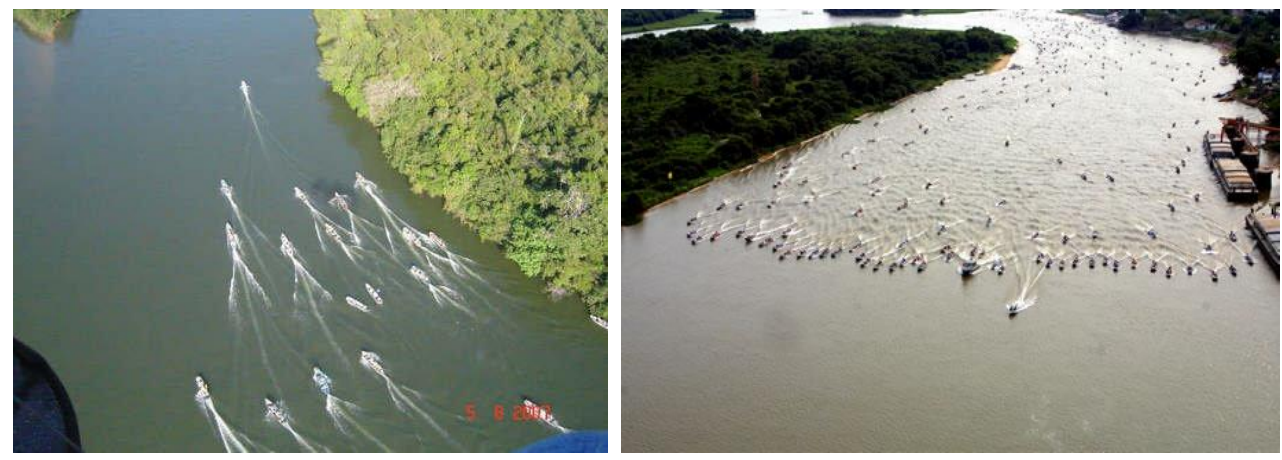

Figure 1: Ship waves at Cuiabá River, Cárceres, MT, Brazil, International Fishing Festival. Source: www.transamerica.com.br

\footnotetext{
1 Engineer, Aquamodelo Consulting and Engineering, Rio de Janeiro, Brazil, mfnascimento@yahoo.com

2 Professor, COPPE, Federal University of Rio de Janeiro, Cx.Postal 68508, Rio de Janeiro, RJ, 21949-900, Brazil, neves@peno.coppe.ufr.j.br

${ }^{3}$ Professor, College of Engineering at Ilha Solteira, São Paulo State University, Ilha Solteira, Brazil, maciel@dec.feis.unesp.br
} 
THE MATHEMATICAL AND NUMERICAL MODELS

FUNWAVE is a hydrodynamic model based on non linear Boussinesq equations (Wei and Kirby, 1995) which simulates most phenomena associated to wave propagation into shallow water. In order to include ship waves, the momentum equations are modified in order to include a moving pressure source at the free surface, which is responsible to generate the waves. In case there are several ships, the forcing term is the result of the linear superposition of each source functions. The following governing equations are thus obtained for the modified model:

Continuity equation

$$
\eta_{t}+\nabla \cdot\left\{(h+\eta)\left[\mathbf{u}_{\alpha}+\left(z_{\alpha}+\frac{1}{2}(h-\eta)\right) \nabla\left(\nabla \cdot\left(h \mathbf{u}_{\alpha}\right)\right)+\left(\frac{1}{2} z_{\alpha}^{2}-\frac{1}{6}\left(h^{2}-h \eta+\eta^{2}\right)\right) \nabla\left(\nabla \cdot \mathbf{u}_{\alpha}\right)\right]\right\}=0
$$

Momentum equation

$$
\begin{aligned}
& \mathbf{u}_{\alpha t}+\left(\mathbf{u}_{\alpha} \cdot \nabla\right) \mathbf{u}_{\alpha}+g \nabla \eta+z_{\alpha}\left\{\frac{1}{2} z_{\alpha} \nabla\left(\nabla \cdot \mathbf{u}_{\alpha t}\right)+\nabla\left(\nabla \cdot\left(h \mathbf{u}_{\alpha t}\right)\right)\right\} \\
& +\nabla\left\{\frac{1}{2}\left(z_{\alpha}^{2}-\eta^{2}\right)\left(\mathbf{u}_{\alpha} \cdot \nabla\right)\left(\nabla \cdot \mathbf{u}_{\alpha}\right)+\frac{1}{2}\left[\nabla \cdot\left(h \mathbf{u}_{\alpha}\right)+\eta \nabla \cdot \mathbf{u}_{\alpha}\right]^{2}\right\} \\
& +\nabla\left\{\left(z_{\alpha}-\eta\right)\left(\mathbf{u}_{\alpha} \cdot \nabla\right)\left(\nabla \cdot\left(h \mathbf{u}_{\alpha}\right)\right)-\eta\left[\frac{1}{2} \eta \nabla \cdot \mathbf{u}_{\alpha t}+\nabla \cdot\left(h \mathbf{u}_{\alpha t}\right)\right]\right\}=-\sum_{j=1}^{J J} \frac{\nabla P_{j}}{\rho}
\end{aligned}
$$

where $\eta$ is the free surface; $h$ is the water depth; $\mathbf{u}_{\alpha}=(u, v)$ is the horizontal velocity at elevation $z$ $=z_{\alpha}=-0.531 h ; g$ is gravity; subscript $t$ indicates partial derivative with respect to time; $\nabla=\left(\frac{\partial}{\partial x}, \frac{\partial}{\partial y}\right)$ is the horizontal gradient operator; and $P_{j}$ is the moving pressure source function for each ship, as proposed by Li e Sclavounos (2002):

$$
P_{j}(x, y)=\rho g D_{j} \cos ^{2}\left(\pi \frac{x}{L_{j}}\right) \cos ^{2}\left(\pi \frac{y}{B_{j}}\right)
$$

valid for $-L_{j} / 2 \leq x \leq L_{j} / 2$ and $-B_{j} / 2 \leq y \leq B_{j} / 2$, where $\rho$ is water density; $D j$ is ship draught; $\left(V_{x}, V_{y}\right)$ is the ship velocity; and $(x, y)$ is the ship position given at any time as $\left(x_{0}+V_{x} t ; y_{0}+V_{y} t\right)$.

Sponge layers are included as boundary conditions for various frequencies and directions, included in the momentum equations.

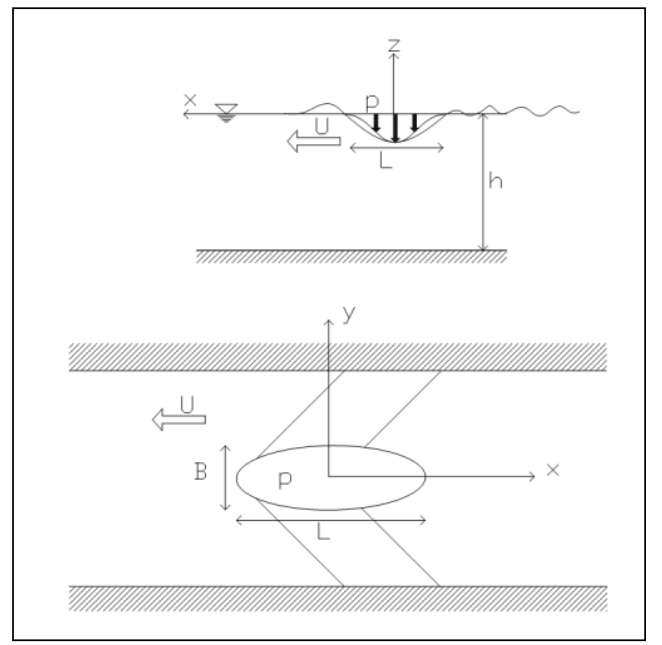

Figure 2: Sketch representation of the moving pressure as the source function which generates the ship waves. 
TESTS AND RESULTS

The bathymetry for all tests consisted of a uniform depth section, a sloping 1:50 bottom, and a constant depth section near to shore, as indicated in Figure 3. Models 1 and 2 were used for comparison of results between single ship and two ships condition. Ship dimensions for all tests were the following: length (L) $82 \mathrm{~m}$, beam (B) $14 \mathrm{~m}$, and draft (D) $5.88 \mathrm{~m}$.

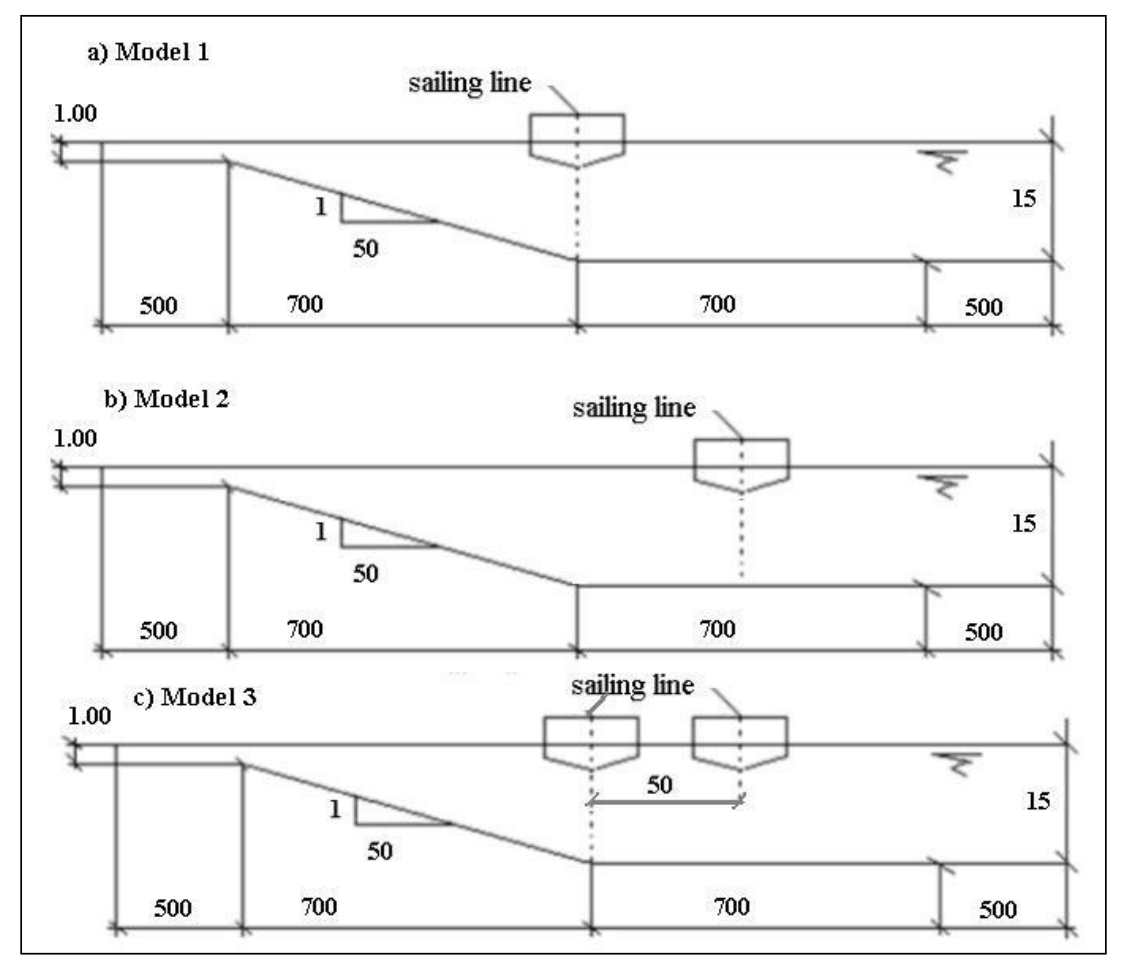

Figure 3: Bottom configuration for the numerical tests. Values are shown in meters.

In order to determine the safe distance between ships, a set of recommendations given by PIANC (1997) apud Alfredini (2005) was used. This distance depends on the ship velocity and the width of the channel, as shown in Figure 4 and Table 1. Considering the distance between the axis of the ships, a value of $50 \mathrm{~m}$ was adopted for all tests.

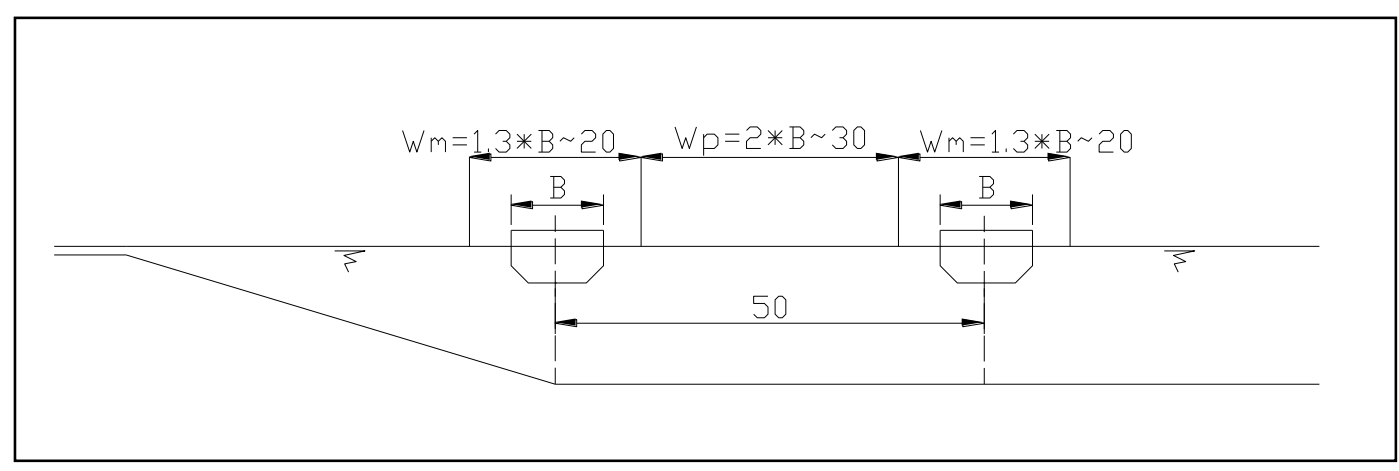

Figure 4: Schematic representation of two ships in a waterway and recommended safety distances between ships (values in meters). 
For the numerical experiments, grid spacing was $\Delta x=5 \mathrm{~m}$ and $\Delta y=8 \mathrm{~m}$, and time steps of 0.1 seconds. The initialization parameters for FUNWAVE+Ship are given in Table 2, where $C E$ is the sponge layer on both sides of the model, $L R$ and $L I$ are the lengths of the constant depth and the inclined portion of the cross section of the channel, $i / i$ is is the bottom slope, $h$ is the water depth at the main channel, and $h d$ is the water depth at the margin. The numerical grid points where the results were obtained (point gauges) are indicated in Figure 5. Tests were conducted for Froude numbers equal to $0.8,1.0$ and 1.1 .

\begin{tabular}{|c|c|c|}
\hline \multirow{2}{*}{$\begin{array}{l}\text { DISTANCE OF } \\
\text { PASSAGE } \\
\text { ship velocity }\end{array}$} & \multicolumn{2}{|c|}{$\begin{array}{c}\text { WP = ADDITIONAL DISTANCE BETWEEN } \\
\text { BOATS }\end{array}$} \\
\hline & Wide channel & Restricted channel \\
\hline fast & $2.0 \mathrm{~B}$ & -- \\
\hline moderate & $1.6 \mathrm{~B}$ & $1.4 \mathrm{~B}$ \\
\hline slow & $1.2 \mathrm{~B}$ & $1.0 \mathrm{~B}$ \\
\hline ship maneuvering & \multicolumn{2}{|c|}{ WM = ADDITIONAL WIDTH FOR EACH BOA } \\
\hline good & \multicolumn{2}{|c|}{$1.3 \mathrm{~B}$} \\
\hline moderate & \multicolumn{2}{|c|}{$1.5 \mathrm{~B}$} \\
\hline bad & \multicolumn{2}{|c|}{$1.8 \mathrm{~B}$} \\
\hline
\end{tabular}

\begin{tabular}{|ccccccc|}
\hline \multicolumn{7}{|l|}{ Table 2: Parameters used in FUNWAVE model. } \\
\hline Test \# & CE $(\mathrm{m})$ & $\mathrm{LR}(\mathrm{m})$ & $\mathrm{LI}(\mathrm{m})$ & $\mathrm{i} / \mathrm{is}$ & $\mathrm{h}(\mathrm{m})$ & $\mathrm{hd}(\mathrm{m})$ \\
\hline ALL & 500 & 700 & 700 & 0.02 & 15 & 1.00 \\
\hline
\end{tabular}

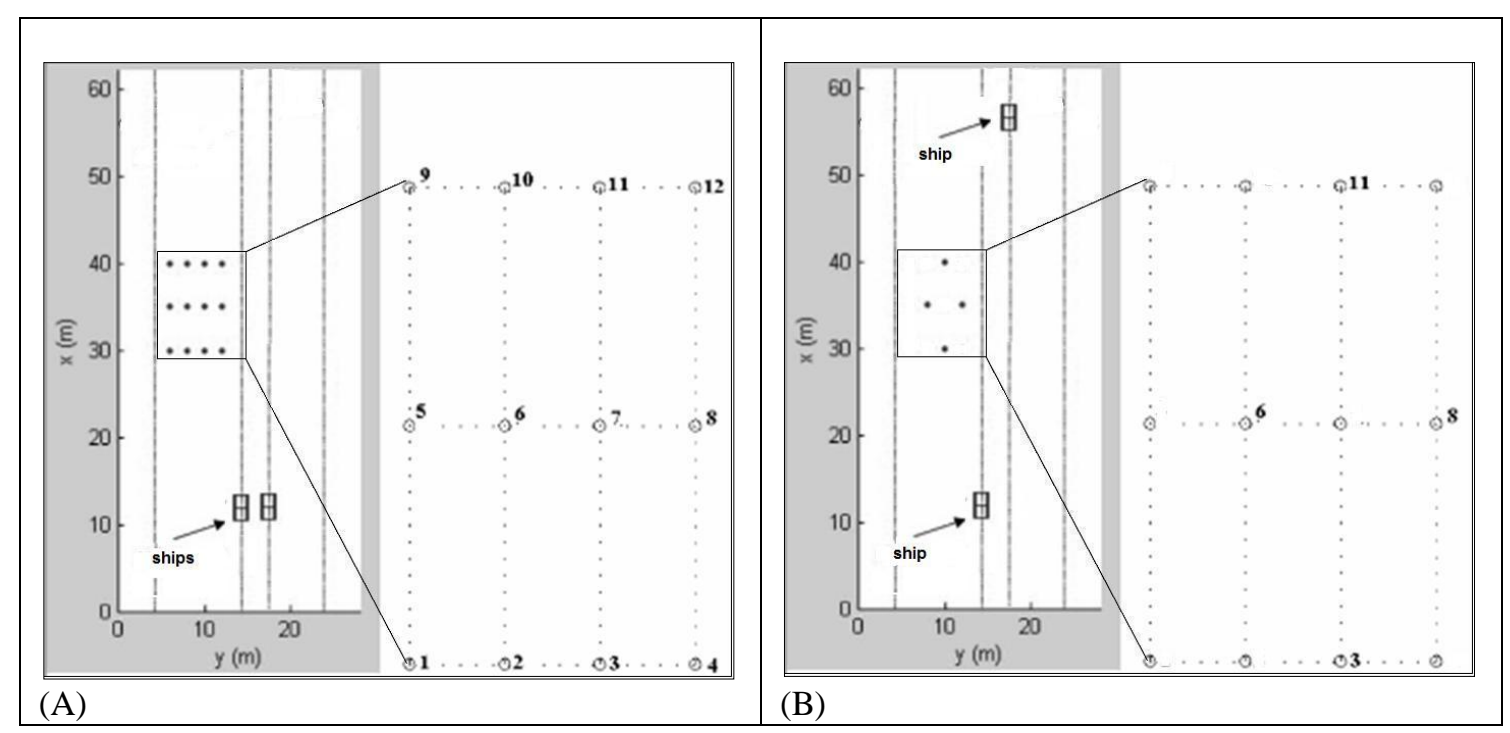

Figure 5: Positioning of numerical wave gauges for: (A) ships following in the same direction; (B) ships in opposite directions. 


\section{Surface Elevation}

Surface elevation for the different tests are shown in the following illustrations (Figure 6 to Figure 8 ), both the two dimensional patterns and the time history of the local surface elevation at selected locations. It should be noted how the wave crests are bent along the slope (left side of the pictures), while in the constant depth region (right side of the pictures) the usual pattern of Kelvin waves is found. Significant differences on the interference pattern are found between the cases when both ships travel in the same or in opposite directions. It also becomes evident, from the inspection on portion (C) and (D) of those figures, that the combined free surface is not equal to the linear superposition of the two wave trains.

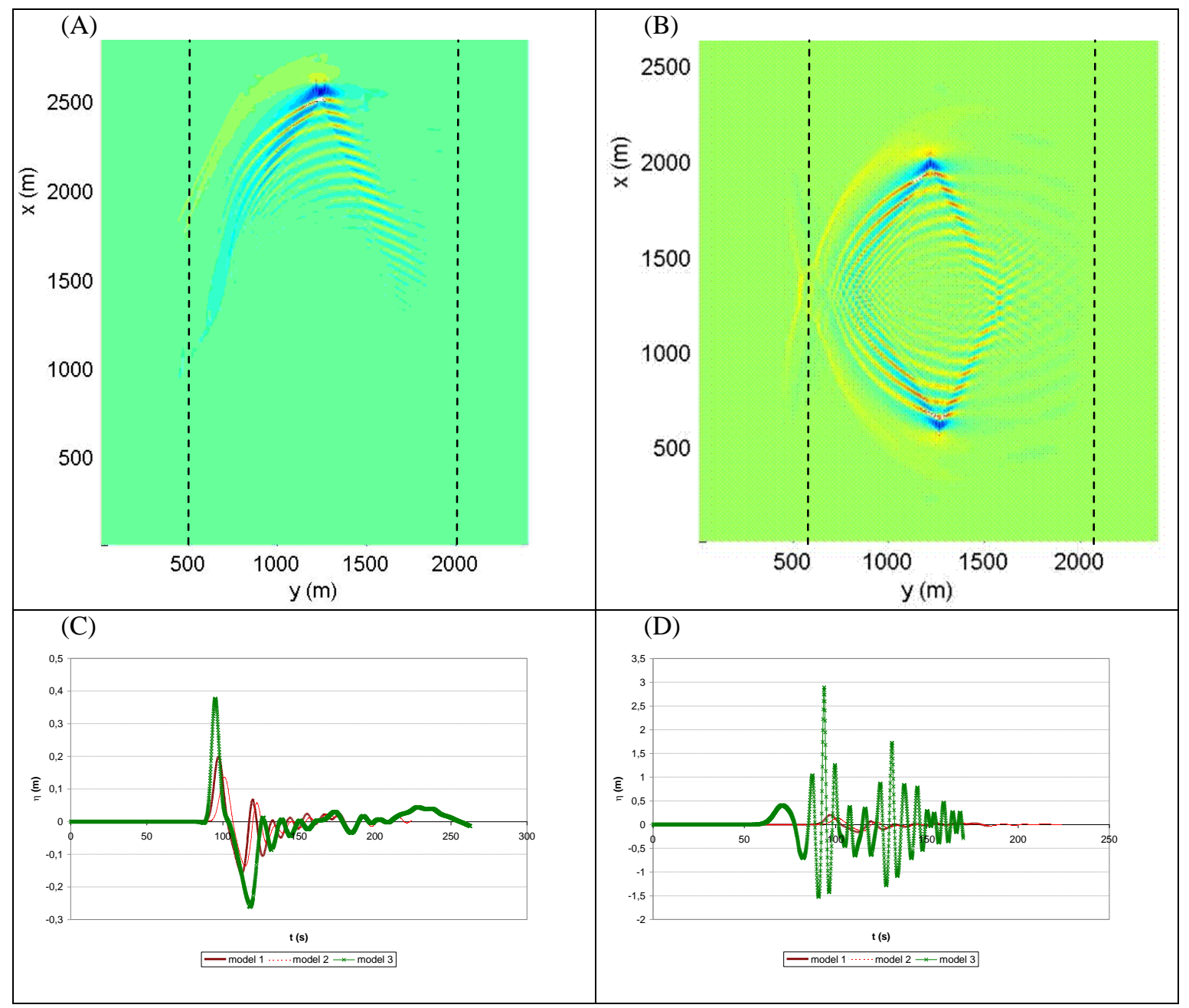

Figure 6: Patterns of interference at free surface for: (A) ships following in the same direction; (B) ships in opposite directions. Time history of surface elevation at point gauge 4 (C), and at point gauge 8 (D). Fh=0.8. 


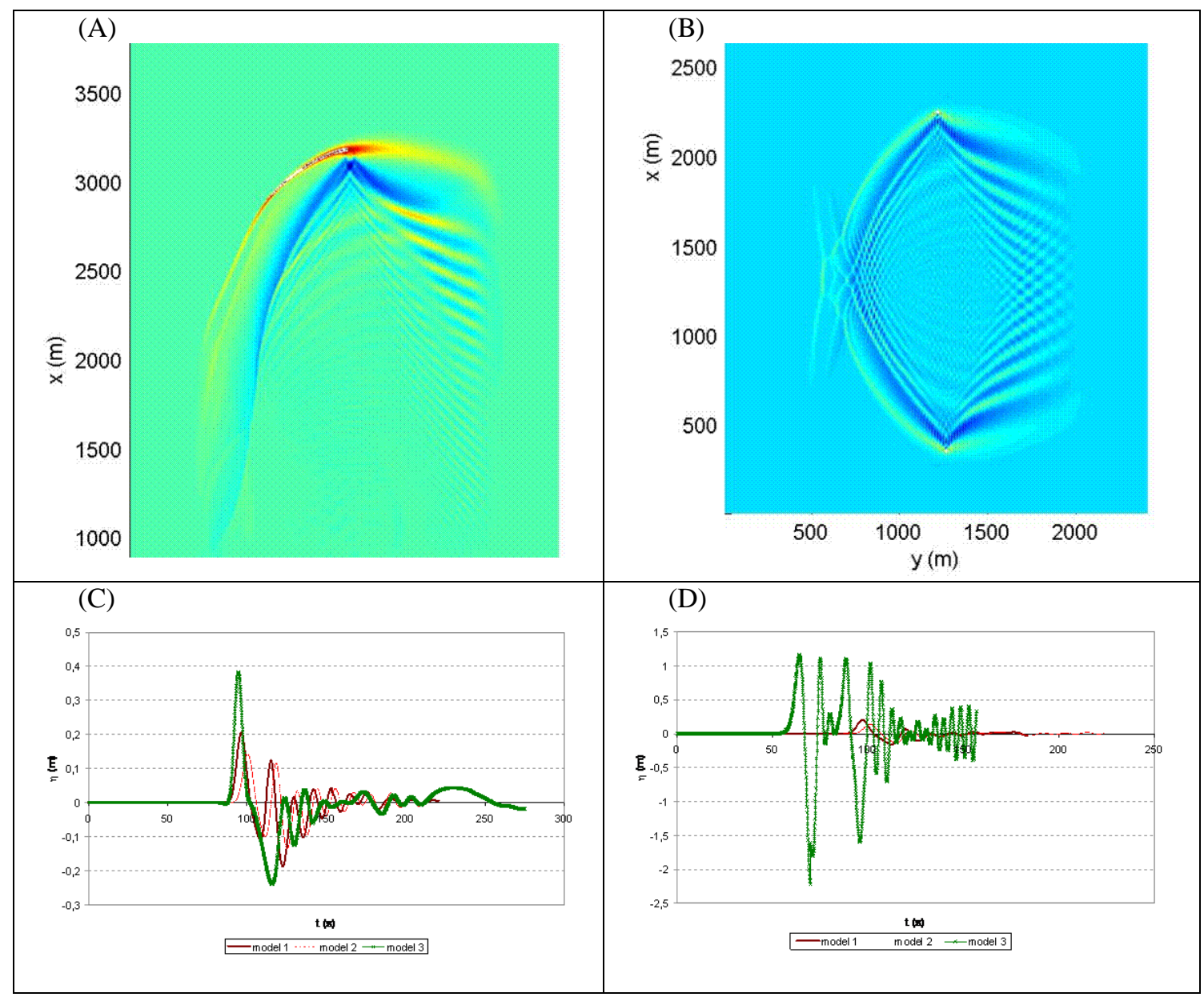

Figure 7: Patterns of interference at free surface for: (A) ships following in the same direction; (B) ships in opposite directions. $\mathrm{Fh}=1.0$. 


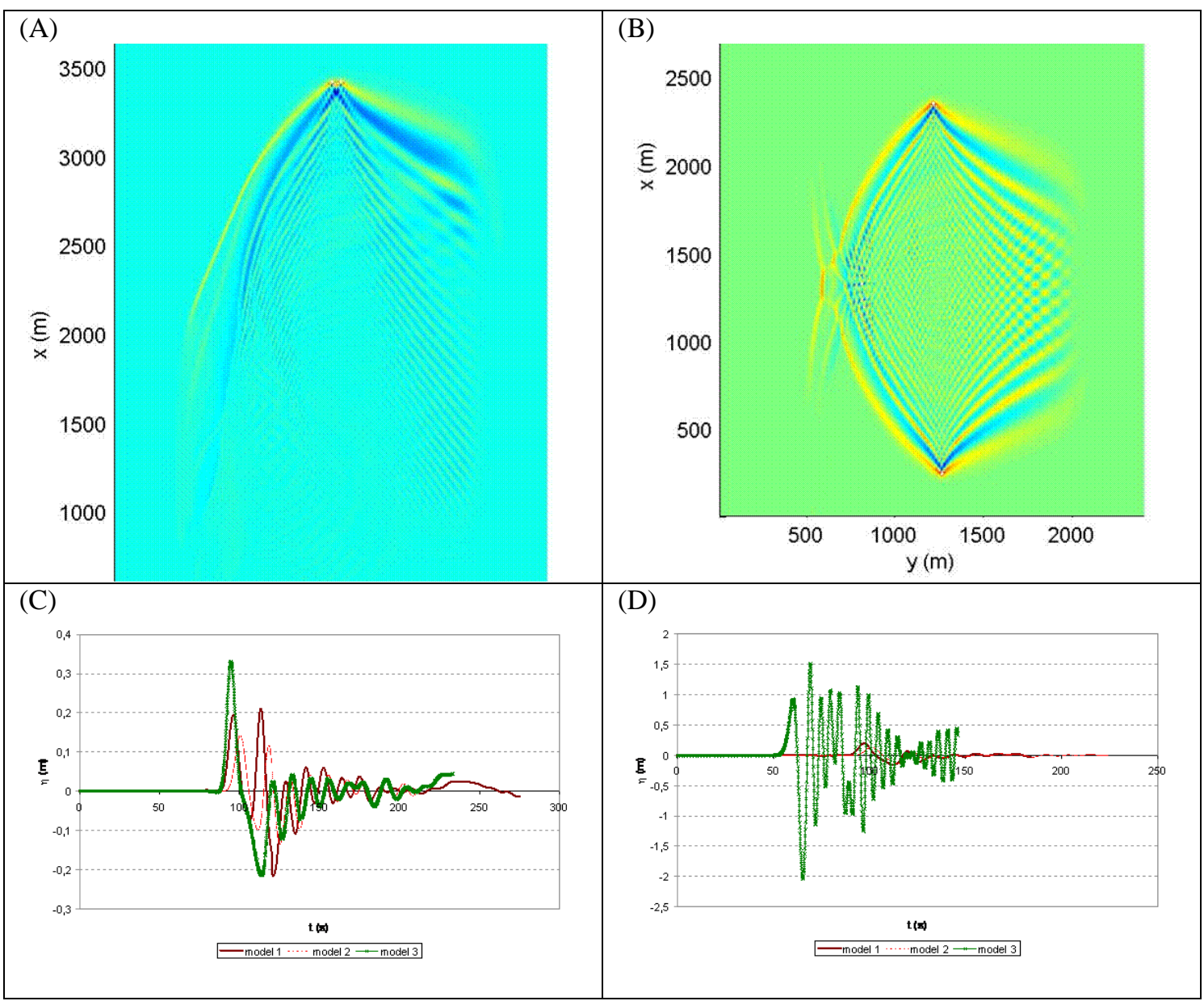

Figure 8: Patterns of interference at free surface for: (A) ships following in the same direction; (B) ships in opposite directions. $\mathrm{Fh}=1.1$. 


\section{Orbital Velocity}

The orbital velocities were computed for the same point gauges shown in Figure 5, considering again ships travelling in the same and in opposite directions. From Figure 9 to Figure 11, the time history of the magnitude of the orbital velocity and the hodographs are shown. Due to nonlinear effects, it should be noted that the combined velocity is no longer the superposition of individual velocities due to each ship. In addition, when looking at the hodograph of the combined flow field, it is interesting to observe the wide variation of direction, thus indicating that a complex pattern of bottom shear stresses or forces upon submerged structures might be anticipated.

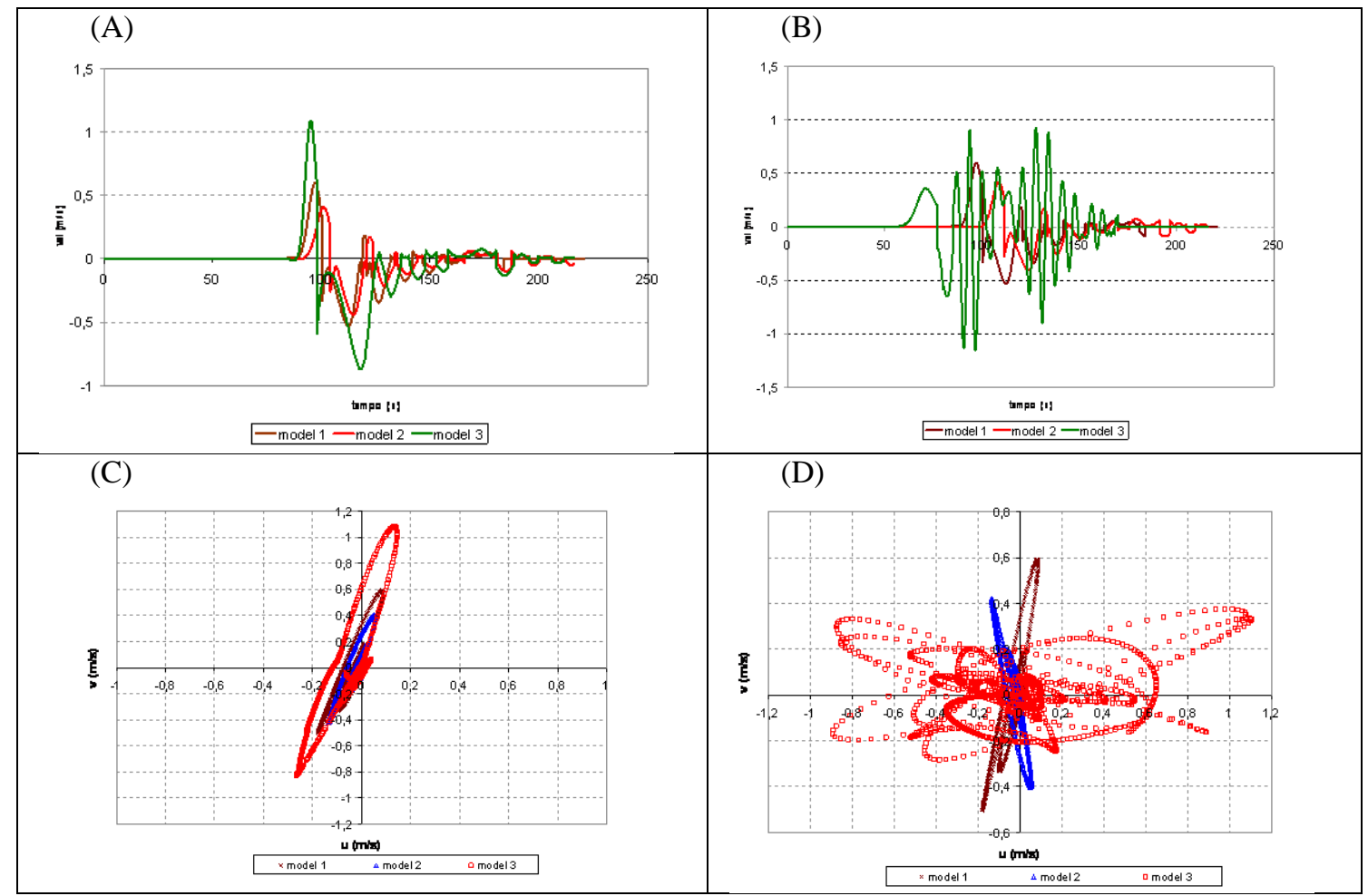

Figure 9: Time history and hodograph of orbital velocities at the bottom for ships following in the same direction (A) and (C); ships in opposite directions (B) and (D). Froude number $\mathrm{Fh}=0.8$. 


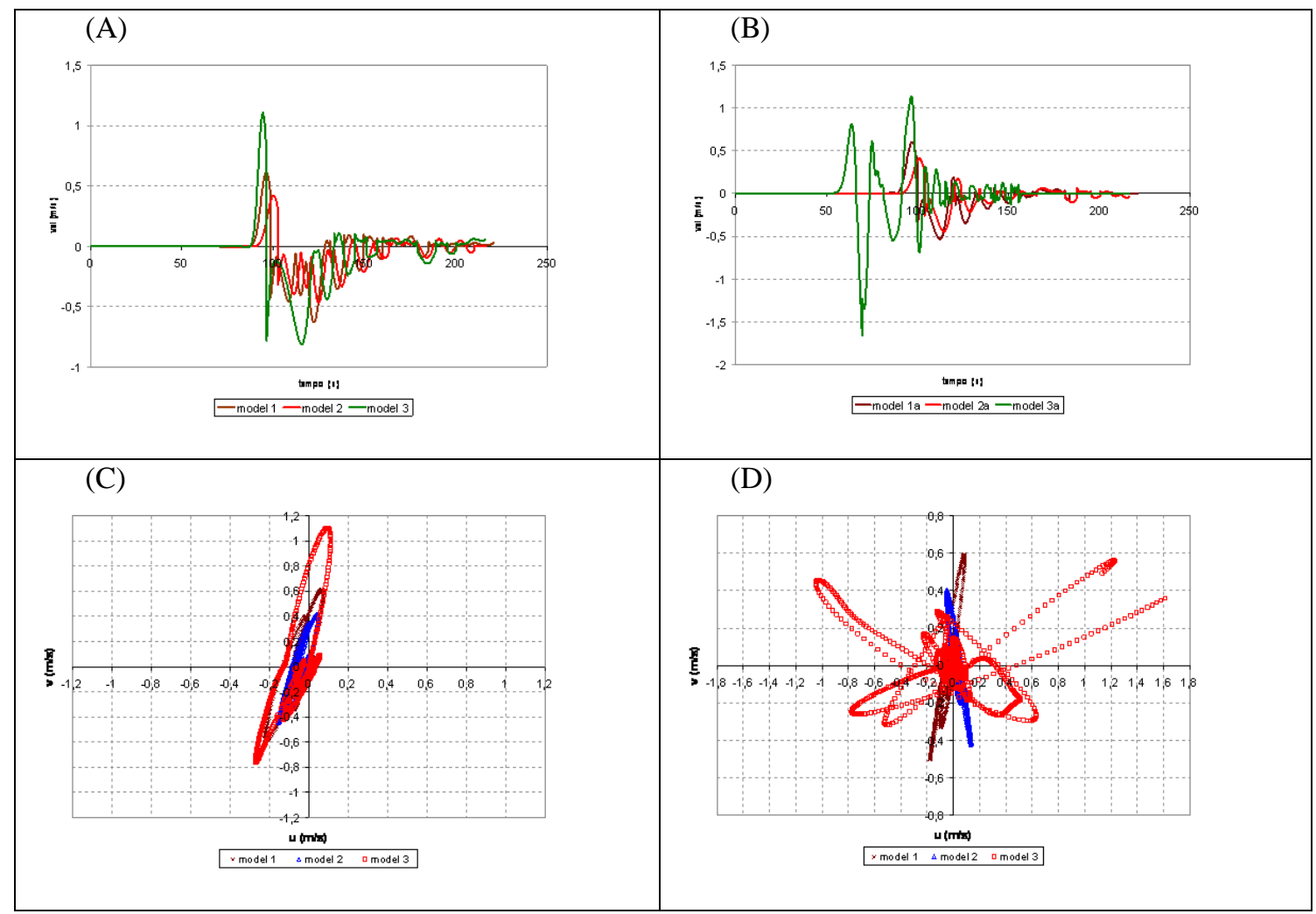

Figure 10: Time history and hodograph of orbital velocities at the bottom for ships following in the same direction (A) and (C); ships in opposite directions (B) and (D). Froude number $\mathrm{Fh}=1.0$.

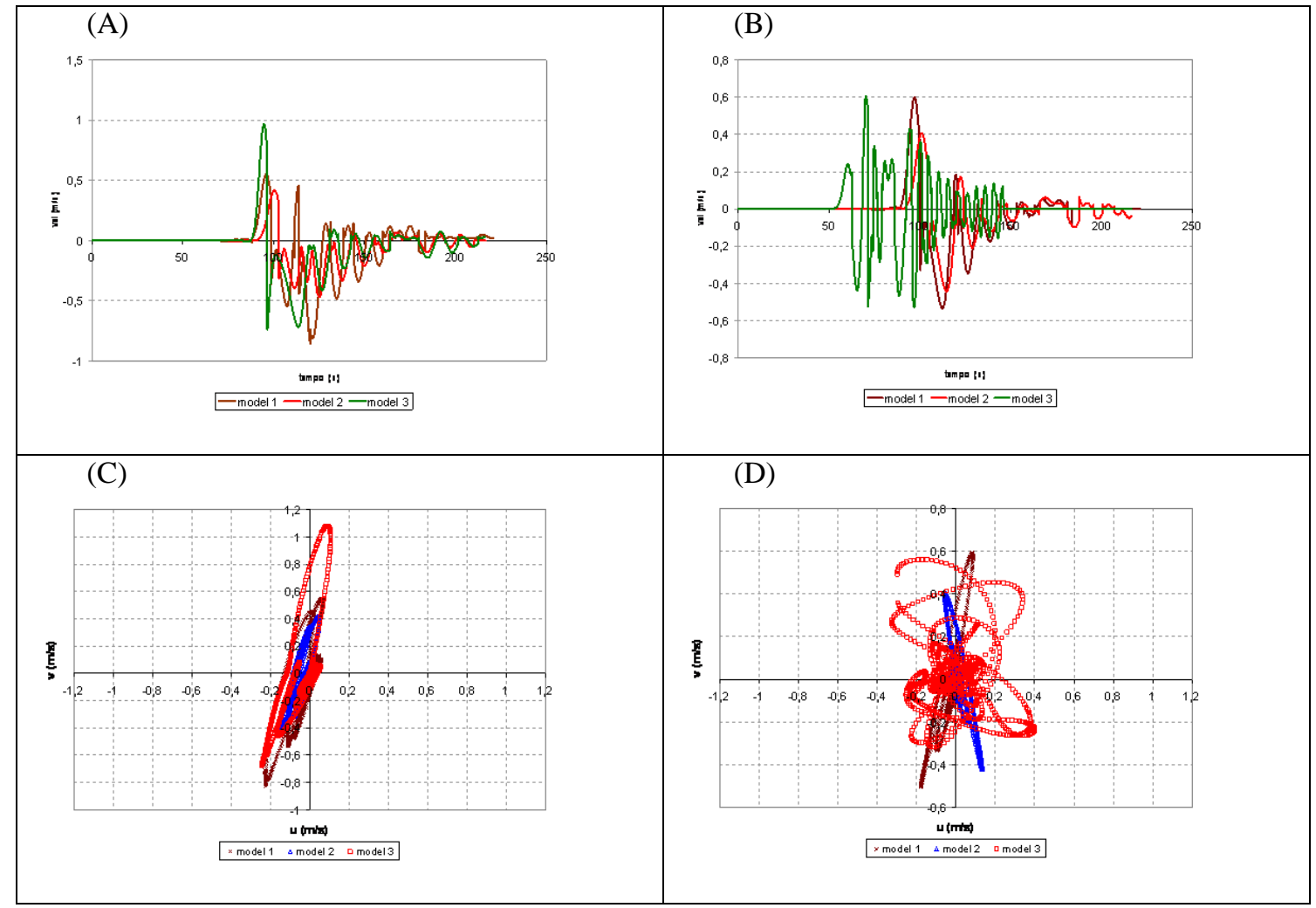

Figure 11: Time history and hodograph of orbital velocities at the bottom for ships following in the same direction (A) and (C); ships in opposite directions (B) and (D). Froude number $\mathrm{Fh}=1.1$. 


\section{DISCUSSION}

The occurrence of waves generated by the simultaneous presence of many ships on a waterway is a common fact and it has been reported as a source of damage to structures and moored boats. For instance, in Guanabara Bay, the traffic of ferry boats between the cities of Rio de Janeiro, Niteroi and Paquetá Island generates enough disturbance to smaller boats, marinas, and oyster growth apparatus that restrictions have been implemented by the local maritime authorities (Figure 12). Apparently, speed restrictions on a single boat are not enough to prevent the cumulative effect of multiple waves generated by various boats, as well as the effects of reflection on seawalls and quays. This hypothesis has been confirmed by the numerical tests.

The interference pattern of ship waves is more complex than that observed for two intersecting long crested waves, for the ship waves are themselves a two dimensional wave pattern. However, the free surface elevation is not sufficient to describe the associated orbital velocities, which are quite different from those observed in wind waves. For this reason, the common engineering practice of using a wind wave of equal height for designing shore structures subject to ship waves should be carefully reviewed.

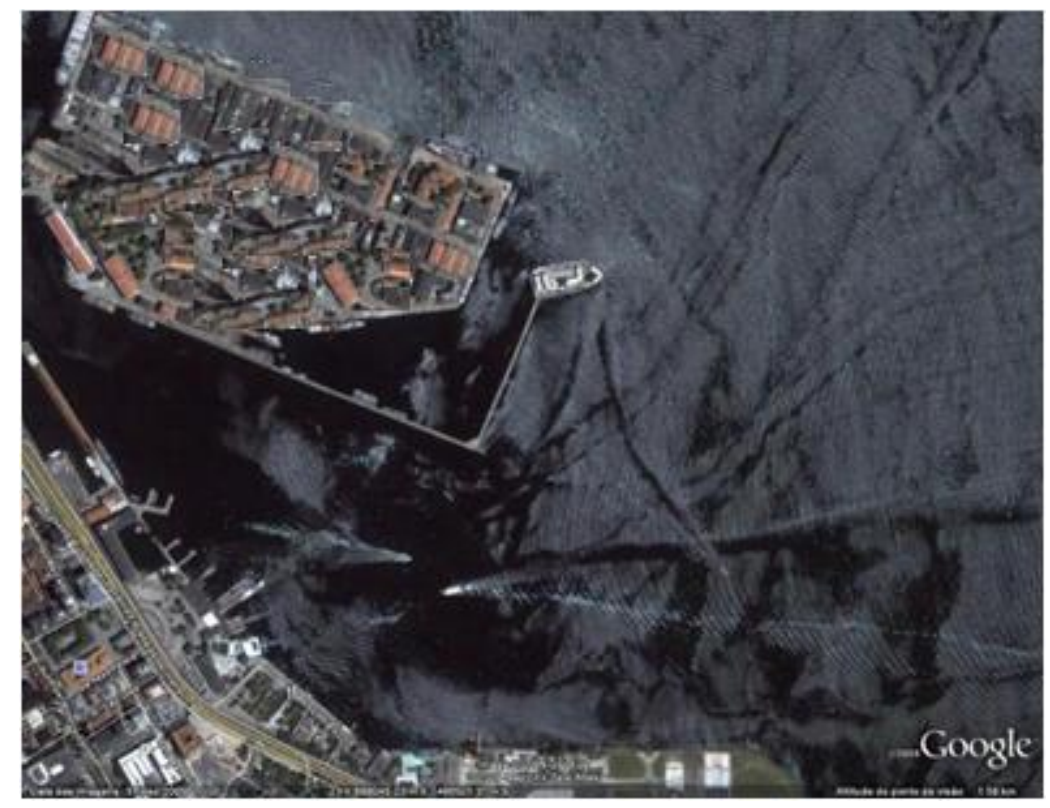

Figure 12: Pattern of crossing ship waves in Guanabara Bay, Rio de Janeiro, Brazil.

Among the several aspects to be considered in the analysis of crossing ship waves the most significant may be the possibility of nonlinear wave-wave interactions and the wide variation in direction of orbital velocities.

Zhu et al. (2008) considered the nonlinear interactions between steady Kelvin waves and an ambient wave, within the wake of a moving ship. By two different methods, using a multiple scale formulation and Zkharov equations, the authors derived the equations which would explain the generation of solitary-type waves due to third-order resonant interactions, on a similar pattern as developed by Philips (1960).

Indeed, in the numerical experiments which were carried on, the model results indicated that the values of the velocity components due to the interaction of both wave trains were higher than the linear summation of the velocities due to each ship separately. In addition, it was also observed that the orbital velocities due to the combined wave field varied widely in direction.

If high-order non-linear interactions may be expected as the result of crossing ship waves, either generating unsteady wave trains or complex wave patterns which cannot be reduced to the linear summation of individual waves, as theoretical and numerical results indicate, further experimental evidence about the phenomenon should be gathered. For instance, in order to correctly quantify sediment transport and morphological evolution of margin and bottom, the bottom shear stresses induced by crossing ship waves and ambient waves should be considered. However, most experimental or theoretical studies is valid exclusively to unidirectional waves (both monochromatic and irregular). By the same reasoning, in order to predict forces on submerged structures or seawalls due to those two- 
dimensional patterns of ship waves, a different approach (experimental and theoretical) should be used by coastal engineers. Current practice of assuming a regular wind wave of same height of one single ship wave seems, at least, questionable.

In case of waterway management and assessment of environmental impacts due to ship waves, for heavy traffic conditions, there is enough evidence that the single establishment of ship velocity limits is not enough. Further investigation on lateral distance and time lag between ships should be conducted by the authors.

\section{CONCLUSION}

FUNWAVE+Ship, including appropriate source function, has provided reasonable solutions in the far field; yet, pressure source functions do not give good results in the near field. Previous tests with the model indicate that the Froude number should be larger than 0.7 .

The methodology here presented allows extension to multiple source functions, in order to simulate the effects of waves generated by many ships. For the present article, though, tests were conducted only for two ships configuration, either traveling in the same or in opposite directions, in order to better illustrate the phenomenon.

In shallow water, the refraction of the interference pattern is significantly different from the pattern in constant depth. It has been observed that the wave pattern generated by two ships is bimodal, twodimensional and more complex than linear superposition. Further, interference peaks are intensified, a phenomenon which may bring additional impacts on marinas and other types of small boat harbors.

Wave orbital velocities are significantly different from wind waves.

Effects on bottom and margin sediment transport, as well as on structures and moored boats, should be carefully studied. Current practice of estimating a ship wave simply by an equivalent wind wave height should therefore be reviewed.

Field and large scale laboratory experiments must be conducted in order to better assess the velocity field associated to crossing ship waves, thus determining bottom stresses and possible resonant interactions.

\section{ACKNOWLEDGMENTS}

This work was funded by Project "Friends of Boussinesq - Cooperative Research Network on Shallow Water and Coastal Hydrodynamics" (CAPES/PROCAD 0144/01-0), and by "Project ONDISA - Wave Monitoring at Ilha Solteira Lake” (FINEP 01.05.0958.00 - Waterway Fund).

\section{REFERENCES}

Alfredini, P., 2005. Obras e Gestão de Portos e Costas - A técnica aliada ao enfoque logístico e ambiental. chapter 11, 313-315, Edgard Blücher, São Paulo.

Chwang, A.T., and Y. Chen. 2003. Field measurement of ship waves in Victoria Harbor. J. Eng.Mechanics, ASCE, 129 (10), 1138-1148.

Li ,Y., and P.D. Sclavounos. 2002. "Three-dimensional nonlinear solitary waves in shallow water generated by advancing", Journal of Fluid Mechanics, v. 470, 383-410.

Nascimento, M.F. 2007. Numerical study of the propagation of ship waves to shallow water (in Portuguese). Doctoral Dissertation. Ocean Engineering Department, Federal University of Rio de Janeiro. Rio de Janeiro, 223pp.

Nascimento, M.F., C.F. Neves, and G.F. Maciel. 2009. Propagation of ship waves on a sloping bottom. Proceedings of $31^{\text {st }}$ International Conference on Coastal Engineering, World Scientific, 540-560.

Phillips, O.M. 1960. The Dynamics of the Upper Ocean. Cambridge University Press, $2^{\text {nd }}$ edition.

PIANC - Permanent International Association of Navigation Congresses, 1997. Approach Channels: AGuide for Design, Boletim No. 95.

Wei, G., and J.T. Kirby. 1995. Time-dependent numerical code for extended Boussinesq equations, $J$. Waterway, Port, Coastal \& Ocean Engg., ASCE, 251-261.

Zhu, Q., Y. Liu, and D. K. P. Yue. 2008. Resonant interactions between Kelvin ship waves and ambient waves, J. Fluid Mech. 597: 171-197. doi: 10.1017/S002211200700969X 